\title{
p41-Arc, a regulatory subunit of Arp2/3 complex, can induce premature senescence in the absence of p53 and $\mathrm{Rb}$
}

\author{
Un-Jung Yun*, Sang-Eun Park* and Deug Y Shin ${ }^{1}$ \\ Department of Microbiology \\ Dankook University College of Medicine \\ Cheonan 330-714, Korea \\ ${ }^{1}$ Corresponding author: Tel; 82-41-550-3878; \\ Fax, 82-41-550-1905; E-mail, dreamer@dku.edu \\ ${ }^{*}$ These authors contributed equally to this work. \\ DOI 10.3858/emm.2011.43.7.042
}

Accepted 10 April 2006

Available Online 1 June 2011

Abbreviations: p41-Arc, actin-related protein $2 / 3$ complex $41 \mathrm{kDa}$ subumit; Arp, actin-related protein; $\mathrm{Rb}$, retinoblastoma protein; $\mathrm{SA}$ $\beta$-Gal, senescence-associated $\beta$-galactosidase

\begin{abstract}
Cellular senescence is a tumor-suppressive process instigated by proliferation in the absence of telomere replication, by cellular stresses such as oncogene activation, or by activation of the tumor suppressor proteins, such as Rb or $\mathrm{p} 53$. This process is characterized by an irreversible cell cycle exit, a unique morphology, and expression of senescence-associated- $\beta$-galactosidase (SA- $\beta$-gal). Despite the potential biological importance of cellular senescence, little is known of the mechanisms leading to the senescent phenotype. p41-Arc has been known to be a putative regulatory component of the mammalian Arp2/3 complex, which is required for the formation of branched networks of actin filaments at the cell cortex. In this study, we demonstrate that p41-Arc can induce senescent phenotypes when it is overexpressed in human tumor cell line, SaOs-2, which is deficient in p53 and Rb tumor suppressor genes, implying that $\mathrm{p} 41$ can induce senescence in a p53-independent way. p41-Arc overexpression causes a change in actin filaments, accumulating actin filaments in nuclei. Therefore, these results imply that a change in actin filament can trigger an intrinsic senescence program in the absence of p53 and $\mathbf{R b}$ tumor suppressor genes.
\end{abstract}

Keywords: p41-Arc, Arp2/3, p53, senescence

\section{Introduction}

The proliferative lifespan of normal mammalian cells is limited by replicative senescence (Hayflick, 1961; Campisi, 1997), a process that appears to be primarily mediated by gradual shortening of telomeres (Shay, 1997). Senescent cells withdraw irreversibly from the cell cycle, but remain viable indefinitely, and display characteristic phenotypic markers, such as enlarged and flattened morphology, irreversible growth arrest, and expression of the senescence-associated- $\beta$-galactosidase (SA$\beta$-Gal) activity at pH 6.0 (Dimri et al., 1995). Recently, it has been shown that expression of ras and raf oncogenes can induce a rapid onset of replicative senescence in normal fibroblast cells associated with induction of p53, p21, p16, and hypophosphorylation of Rb protein (Serrano et al., 1997; Zhu et al., 1998), implicating that replicative senescence, like apoptosis, is a programmed response of the organism to potentially oncogenic impact.

Tumor cells are capable of extended proliferation as if the capability to become senescent has been somehow repressed or lost. Recently we and other groups have reported that certain tumor cells enter into senescence state by expression of tumor suppressor genes such as p53 (Shin et al., 1997), $\mathrm{Rb}$ (Xu et al., 1997), p21 (Fang et al., 1999), and p16 (Uhrbom et al., 1997). Although these studies suggest that tumor suppressor genes are essential for oncogene-induced senescence in normal HDF and their expression can induce senescence in human tumor cells, detailed mechanisms of senescence induction have not been understood. There is therefore a great deal of interest in identifying genes that can trigger an intrinsic senescence program.

The Arp $2 / 3$ complex may be a key mediator of actin polymerization by nucleating new actin filaments and cross-links them from end to side-branch, thus creating new barbed ends which drove the extension of the cell's leading edge of motile cells, specifically at the junction of the $\mathrm{Y}$ branches (Higgs and Pollard, 1999). The Arp2/3 complex consists of seven subunits (Arp2, Arp3, Arc-p16, Arc-p20, Arcp21, Arc-p34 and Arc-p41) (Welch, 1999) (Mullins and Pollard, 1999). Arc-p41 is proposed to have a regulatory role, facilitating assembly and maintenance of the Arp2/3 complex. However, it remains unknown for the functions of p41-Arc in cell growth regula- 


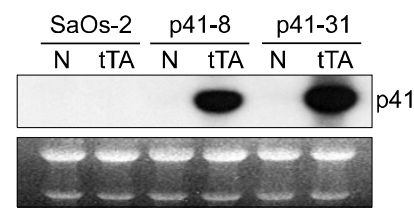

Figure 1. Inducible expression of p41-Arc in SaOs-2 cells. Two stable cell lines carrying ptet-p41 were infected with a recombinant adenovirus encoding tTA. Northern blot analysis was hybridized with 32P-labed full cDNA of p41-Arc. rRNA were used as a loading control.

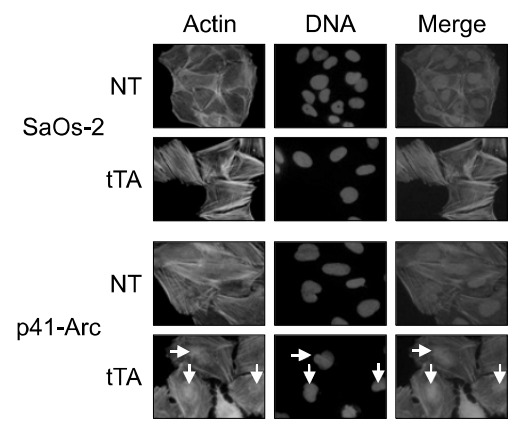

Figure 2. Accumulation of actin filament in nuclei in cells expressing p41-Arc. Cells were infected with tTA-encoding adenovirus and incubated for 4 days. The cells were immunostained with RITC-conjugated phallodin, which specifically binds to actin filaments (Red). After washing, nuclei were stained with DAPI (Blue). Arrows indicate nuclei accumulating actin filaments.

tion (Welch, 1999; Gournier et al., 2001).

In this study, we examined a role of p41-Arc in cellular growth and differentiation. For this, we examined the effects of p41-Arc expression and found that p41-Arc can induce senescence in tumor cell, SaOs-2 lacking p53 and Rb tumor suppressors.

\section{Results}

To investigate a role of $\mathrm{p} 41-\mathrm{Arc}$, we attempted to constitutively express p41-Arc in SaOs-2. However, stable transfectants were not obtained because cells expressing p41-Arc fail to grow (data not shown). Therefore, we examined an inducible expression of p41 using tetracycline-regulated gene expression system (Gossen and Bujard, 1992, Jung et al., 2001). To this end, we constructed a plasmid, ptet-p41Arc, in which p41-Arc cDNA is under the control of a tetracycline-repressible promoter, expression from this promoter requires the tTA transactivator that binds to and activates the tetracycline-regulated promoter in the absence of tetracycline (Gossen and Bujard, 1992). ptet-p41Arc was transfected into SaOs-2 cells and more than 10 stable clones were obtained. To achieve p41-Arc expression we infected the cells with a

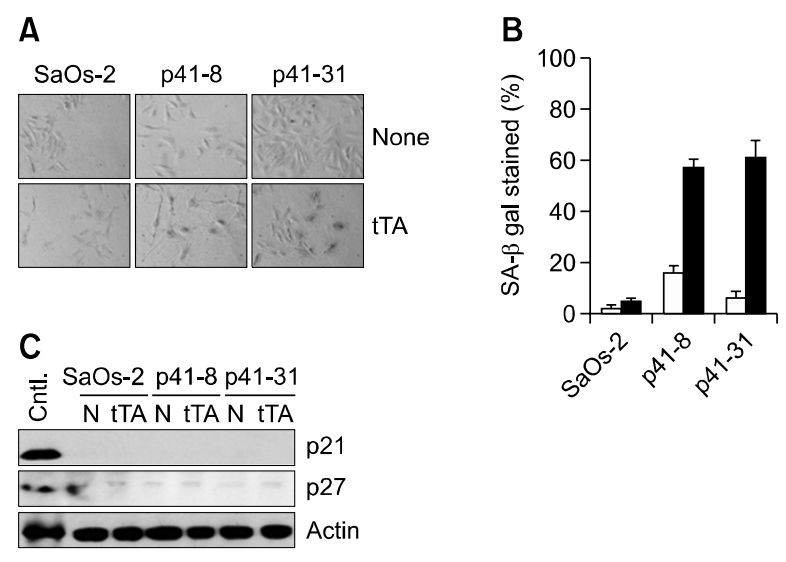

Figure 3. p41-Arc induces senescence in p53-deficient tumor. (A) SA- $\beta$-gal staining and morphology 6 days after infection with tTA-encoding adenovirus in SaOs-2 and its stable transfectants harboring ptet-p41. (B) Proportion of SA- $\beta$-gal stained cells. The cells as in (A) were washed and fixed with $0.25 \%$ glutaraldehyde in PBS for $15 \mathrm{~min}$ at room temperature and stained at pH 6.0 as described in Materials and Methods. (C) Expression of p21 and p27 in SaOs-2 cells and its transfectants harboring ptet-p41 infected with tTA-virus.

recombinant adenoviruses encoding tTA (Figure 1). After infection with tTA virus, mRNA levels of p41-Arc was dramatically increased (Figure 1). Expression of p41 was induced in more than 2 clones following infection with the tTA-encoding adenovirus in the absence of tetracycline.

It has been shown that p41-Arc has a regulatory role, facilitating assembly and maintenance of the Arp $2 / 3$ complex, which nucleates and cross-links actin filaments from end to side-branch, thus creating new barbed ends which drove the extension of the cell's leading edge in motile cells, specifically at the junction of the $\mathrm{Y}$ branches (Higgs and Pollard, 1999). Thus, we examined whether p41-Arc expression affects actin filaments. Figure 3 showed that nuclear actin filaments were increased in cells expressing p41-Arc, but that in the cytosol was not affected (Figure 2), implying that overexpression of p41-Arc facilitates nucleation and cross-linking of nuclear actin filaments.

Growth of cells carrying ptet-p41 was arrested by the infection with tTA-encoding adenovirus (data not shown). However, those cells became flattened and enlarged just like senescent cells as previously reported (Figure 3A). It has been shown that senescent, but not quiescent or terminally differentiated cells express SA- $\beta$-gal activity, which can be detected by incubating cells at $\mathrm{pH} 6.0$ with 5Bromo-4-chloro-3-indoryl $\beta$-D-galactoside (X-gal) (Dimri et al., 1995). Thus, we examined whether the cells infected with tTA-encoding adenovirus express SA- $\beta$-gal activity. As shown Figure 2B, $>50 \%$ of cells became to express SA- $\beta$-gal activity 
A

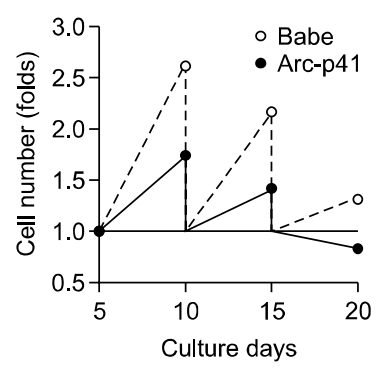

B

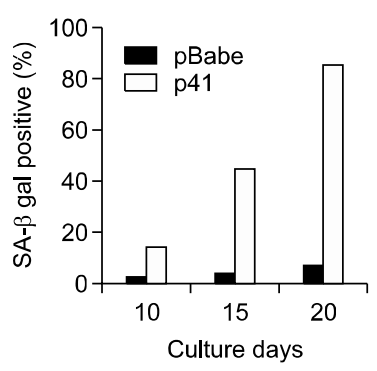

C pBabe p41

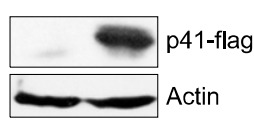

Figure 4. p41-Arc induces senescence in human diploid fibroblasts. (A) Growth of HDF expressing p41-Arc. HDF at passage 15 were retrovirally transduced with p41 or empty vector (pBabe). $1 \times 10^{4}$ of puromycin-resistant cell pools were grown for the indicated periods and then cell numbers were counted at each passage. (B) Proportion of SA- $\beta$-gal stained HDF. SA- $\beta$-galactosidase activity was assayed at each passage. (C) Expression of $p 41-A r c$ in HDF.

at 9 days after infection with the tTA-encoding virus, whereas control cells infected with the $\Delta \mathrm{E} 1$ control virus showed no activity (Figure $3 \mathrm{~B}$ ). Because SaOs-2 cells are deficient for p53 and Rb tumor suppressor genes, expression of other cell cycle regulators such as p21 and p27 were examined. Both cell cycle regulators were not affected during p41-Arc-induced senescence, implying that p41Arc induces senescence in the absence of cell cycle regulators such as p53, pRb, p21, and p27 (Figure 3).

Growth inhibitory role of p41-Arc was also examined in human diploid fibroblast (HDF) cells. HDF cells were infected with retrovirus expressing p41-Arc and cultured to examine cell growth. Growth of HDF was significantly inhibited by p41Arc and ceased after second passage (Figure 4A). Appearance of SA- $\beta$-galactosidase-positive cells was increased after first passage at day 10 (Figure $4 \mathrm{~B}$ ), implying that $\mathrm{p41}$ rapidly induces senescence in human fibroblasts.

\section{Discussion}

The present study suggests that overexpression of p41-Arc facilitates nucleation and cross-linking of nuclear actin filaments and induction of senescence in human tumor and normal fibroblasts. Because overexpression of $\mathrm{p} 41$-Arc results in an inhibition of cell growth, the effects of p41-Arc in actin filaments have not been reported yet. However, inducible expression of p41-Arc allows us to find two phenotypes, senescence and nuclear accumulation of actin filaments. However, it remains to be elucidated how p41-Arc overexpression results in the accumulation of actin filament in nuclei and this change in cytoskeleton affects cell growth and senescence. In support, it has been shown that expressions of the p41-Arc in human gastric cancers are significantly lower than those in the normal samples, implying that the reduced expression of p41-Arc might be involved in gastric cancer development or progression (Kaneda et al., 2002).

In addition, tumor suppressors, such as p53 and $\mathrm{Rb}$, have been demonstrated to be important for entering senescent state from the cell cycle (Shin et al., 1997, Xu et al., 1997). Intra- and extra-cellular signals for inducing senescence activate the tumor suppressors, which in turn arrest the cell cycle and activate senescence programs. However, SaOs-2 cells are deficient for p53 and Rb (Hendricks-Taylor and Darlington, 1995). Therefore, these results suggest that p41-Arc activates a senescence program in p53- and Rb-independent ways.

\section{Methods}

\section{Cell culture and DNA transfection}

SaOs-2 human sarcoma cells were maintained in DMEM supplemented with $10 \%$ FBS (GIBCO BRL) and penicillinstreptomycin $(50 \mathrm{U} / \mathrm{ml})$. To establish SaOs-2 cells expressing p41-arc, full length cDNA of p41-Arc was cloned into $\mathrm{BamHI}$ and Hind III sites of pTet-off vector and constructed ptet-p41. We transfected cells with ptet-p41Arc and selected individual clones of stable transfectants, designated SaOs2p41, for further analysis. To induce p41 expression, we infected cells a recombinant adenovirus encoding tTA (obtained from Dr. Morgan) for 3-4 h (Park et al., 2000). The infected cells were maintained in DMEM supplemented with $1 \%$ FBS in order to prevent loss of the adenovirus.

\section{Senescence-associated $\beta$-galactosidase (SA- $\beta$-Gal) staining}

Cells were washed in PBS, and fixed with $0.25 \%$ glutaraldehyde in PBS for $15 \mathrm{~min}$ at room temperature. SA- $\beta$-gal activity at $\mathrm{pH} 6.0$ was detected by incubation at $37^{\circ} \mathrm{C}$ for $6-8$ hrs with fresh SA- $\beta$-gal staining solution (Dimri et al., 1995).

\section{Immunofluorescence of actin filaments}

Cells were grown onto glass cover slips in 6 well plates The cells on cover glass were washed with PBS and fixed with $3.7 \%$ paraformaldehyde and permeabilized with $0.5 \%$ Triton X-100 for 15 mins. Cells were blocked with $3 \%$ Bovine serum albumin (BSA) in PBS-0.1\% Tween 20 for 2 $\mathrm{h}$ and washed PBS containing $0.1 \%$ Tween 20 . Fixed cells 
were incubated with phalloidin-RITC for $1 \mathrm{~h}$. After washes with PBS- $0.1 \%$ Tween 20 , the cells on cover slip were stained with 4',6-diamidino-2-phenylindole (DAPI, $1 \mu \mathrm{g} / \mathrm{ml}$ ) for $10 \mathrm{~min}$, washed with PBS-0.1\% Tween 20 and mounted on Slide glass using mounting medium (Biomeda corp.) and were observed under a fluorescence microscope.

\section{Northern blot analysis}

Total cellular RNA was isolated with the use of Trizol solution (Invitrogen). Then $20 \mu \mathrm{g}$ of total RNA per sample was denatured, applied for SDS-PAGE, transferred by capillarity to a nylon membrane and hybridized as described in the manufacturer's instructions (Expresshyb \& Clonetech). Probes were $32^{P}$-labed full length cDNA using a random primer DNA labeling kit (Roche). The Blots were exposed on X-ray film at $-70^{\circ} \mathrm{C}$ overnight after being washed.

\section{Western blot analysis}

The cell lysates were prepared as previously reported (Yun et al., 1999). Briefly, the cells were lysed with RIPA buffer [50 mM Tris ( $\mathrm{pH}$ 7.5), $5 \mathrm{mM} \mathrm{NaCl}, 1 \mu \mathrm{M}$ EGTA, 1\% Triton $\mathrm{X}-100,50 \mu \mathrm{M} \mathrm{NaF}, 10 \mu \mathrm{M}$ Na3VO4, $1 \mu \mathrm{g} / \mathrm{ml}$ aprotinin, 1 $\mu \mathrm{g} / \mathrm{ml}$ leupeptin, $1 \mu \mathrm{g} / \mathrm{ml}$ pepstatin $\mathrm{A}, 0.1 \mathrm{mM}$ PMSF and 1 $\mathrm{mM}$ DTT], and the lysates were clarified by centrifugation $\left(1,200 \mathrm{rpm}\right.$ for $10 \mathrm{~min}$ at $\left.4^{\circ} \mathrm{C}\right)$. The total cell extracts were separated on SDS-polyacrylamide gel, and the proteins were transferred to a PVDF membrane (NEN Life Science Products, Boston, MA). Western blot was performed with ECL Western blotting detection reagents (Amersham Pharmacia Biotech, Sweden).

\section{Acknowledgements}

This work was supported by the Research Program of Dual Regulation of Cancer-Aging and Basic Research Capability Enhancement program from National Research Foundation of Korea (NRF-353-2009-2-C00059) funded by the Korean Ministry of Education Science and Technology.

\section{References}

Campisi J. The biology of replicative senescence. Eur J Cancer 1997;33:703-9

Dimri GP, Lee X, Basile G, Acosta M, Scott G, Roskelley C, Medrano EE, Linskens M, Rubelj I, Pereira-Smith O, et al. A biomarker that identifies senescent human cells in culture and in aging skin in vivo. Proc Natl Acad Sci USA 1995;92:9363-7

Fang L, Igarashi M, Leung J, Sugrue MM, Lee SW, Aaronson SA. p21Waf1/Cip1/Sdi1 induces permanent growth arrest with markers of replicative senescence in human tumor cells lacking functional p53. Oncogene 1999;18:2789-97

Gossen M, Bujard H. Tight control of gene expression in mammalian cells by tetracycline-responsive promoters. Proc Natl Acad Sci USA 1992;89:5547-51

Gournier H, Goley ED, Niederstrasser H, Trinh T, Welch MD.
Reconstitution of human Arp2/3 complex reveals critical roles of individual subunits in complex structure and activity. Mol Cell 2001;8:1041-52

Hayflick L. The serial cultivation of human diploid strains. Exp Cell Res 1961;25:585-621

Hendricks-Taylor LR, Darlington GJ. Inhibition of cell proliferation by C/EBP alpha occurs in many cell types, does not require the presence of $\mathrm{p} 53$ or $\mathrm{Rb}$, and is not affected by large T-antigen. Nucleic Acids Res 1995;23:4726-33

Higgs HN, Pollard TD. Regulation of actin polymerization by Arp2/3 complex and WASp/Scar proteins. J Biol Chem 1999;274:32531-4

Jung MS, Yun J, Chae HD, Kim JM, Kim SC, Choi TS, Shin DY. p53 and its homologues, p63 and p73, induce a replicative senescence through inactivation of NF-Y transcription factor. Oncogene 2001;20:5818-25

Kaneda A, Kaminishi M, Nakanishi Y, Sugimura T, Ushijima T. Reduced expression of the insulin-induced protein 1 and p41 Arp2/3 complex genes in human gastric cancers. Int J Cancer 2002;100:57-62

Mullins RD, Pollard TD. Structure and function of the Arp2/3 complex. Curr Opin Struct Biol 1999;9:244-9

Park M, Chae HD, Yun J, Jung M, Kim YS, Kim SH, Han MH, Shin DY. Constitutive activation of cyclin B1-associated cdc2 kinase overrides p53-mediated G2-M arrest. Cancer Res 2000;60:542-5

Serrano M, Lin AW, Mccurrach ME, Beach D, Lowe SW. Oncogenic ras provokes premature cell senescence associated with accumulation of p53 and p16INK4a. Cell 1997;88:593-602

Shay JW. Molecular pathogenesis of aging and cancer: are telomeres and telomerase the connection? J Clin Pathol 1997;50:799-800

Shin DY, Sugrue MM, Lee SW, Aaronson SA. Wild-type p53 triggers a rapid senescence program in human tumor cells lacking functional p53. Proc Natl Acad Sci USA 1997; 94:9648-53

Uhrbom L, Nister M, Westermark B. Induction of senescence in human malignant glioma cells by $\mathrm{p} 16 \mathrm{INK} 4 \mathrm{~A}$. Oncogene 1997; $15: 505-14$

Welch MD. The world according to Arp: regulation of actin nucleation by the Arp2/3 complex. Trends Cell Biol 1999;9:423-7

Xu HJ, Zhou Y, Ji W, Perng GS, Kruzelock R, Kong CT, Bast $\mathrm{RC}$, Mills GB, $\mathrm{Li} J$, Hu SX. Reexpression of the retinoblastoma protein in tumor cells induces senescence and telomerase inhibition. Oncogene 1997;15:2589-96

Yun J, Chae HD, Choy HE, Chung J, Yoo HS, Han MH, Shin DY. p53 negatively regulates cdc2 transcription via the CCAAT-binding NF-Y transcription factor. J Biol Chem 1999; 274:29677-82

Zhu J, Woods D, Mcmahon M, Bishop J M. Senescence of human fibroblasts induced by oncogenic Raf. Genes Dev 1998;12:2997-3007 